\title{
LA PRENSA RELIGIOSA EN ARGENTINA Y MÉXICO COMO HERRAMIENTA MODERNA DE LA REFORMA ULTRAMONTANA. 1840-1870*
}

\author{
POR \\ IGNACIO MARTÍNEZ ${ }^{1}$ \\ IECH, CONICET - Universidad Nacional de Rosario
}

\begin{abstract}
RESUMEN
Se estudian rasgos comunes de periódicos religiosos de México y Argentina editados entre las décadas de 1840 y 1870 . En la primera sección se señalan indicadores de modernización en las formas y el contenido de los periódicos analizados que dan cuenta de una adaptación a los hábitos de lectura y la sensibilidad religiosa de un público nuevo. En la segunda se identifican las notas donde sus redactores abogan por una salida ultramontana en la disputa interna sobre las formas de autoridad de la Iglesia y su relación con el poder temporal.
\end{abstract}

PALABRAS CLAVE: modernidad; ultramontanismo; prensa religiosa; México; Argentina; Siglo XIX.

\section{RELIGIOUS PRESS IN ARGENTINA AND MEXICO AS A MODERN TOOL FOR ULTRAMONTANE REFORM. 1840-1870}

\begin{abstract}
In this paper I study common features of religious newspapers in Mexico and Argentina between 1840s and 1870s. In the first section, I analyze those signs of modernization in forms and contents showing adaptation to reading habits and religious sensibility of a new public. In the second one, I study those articles seeking for an ultramontane alternative in the internal conflicts on the Church's ways of rule and its relationship with temporal power.
\end{abstract}

KEY WORDS: modernity; ultramontanism; religious press; Mexico; Argentina; 19th Century.

Cómo CITAR este artículo / Citation: Martínez, Ignacio. 2019. «La prensa religiosa en Argentina y México como herramienta moderna de la reforma ultramontana. 1840-1870». Hispania Sacra 71, 144: 659-668. https://doi.org/10.3989/hs.2019.047

Recibido/Received 14-02-2018

Aceptado/Accepted $\quad$ 06-11-2018

\section{INTRODUCCIÓN}

En este artículo examino algunos rasgos de la prensa religiosa de México y Argentina en las décadas centrales del siglo XIX. Me interesa dar cuenta de una serie de novedades relacionadas con la transformación vivida por el catolicismo hispanoamericano en la transición del Antiguo Régimen a las sociedades contemporáneas. En primer lugar, analizo

* Deseo agradecer a Roberto Di Stefano por los comentarios hechos a la primera versión de este artículo, a Erika Pani por sus valiosas sugerencias bibliográficas y a los evaluadores anónimos de Hispania Sacra por sus observaciones.

1 igntinez@gmail.com /

ORCID iD: https://orcid.org/0000-0002-3343-1283 el modo en que los editores se preocuparon por hacer de la prensa religiosa una lectura atractiva con el objetivo de ampliar su público, al tiempo que buscaban reforzar la identidad católica transnacional. En segundo término, estudio el modo en que en las páginas de estos periódicos se concebía la autoridad en materia religiosa y qué imagen del sacerdocio intentaba instalarse.

Aunque parezcan dos temas algo alejados entre sí, me sirven aquí como argumentos complementarios para demostrar una misma hipótesis. Creo que la prensa religiosa fue en muchos casos la herramienta que utilizaron los impulsores de una manera particular, no la única, de entender el catolicismo y la Iglesia para desplazar a otras concepciones posibles dentro del mundo católico. Para Iberoamérica, me 
refiero al desplazamiento que sufrieron las concepciones y prácticas del clero galicano por una forma e idea de la Iglesia que han sido comúnmente denominadas ultramontanas. En esa puja por la definición de la ortodoxia católica los periódicos ultramontanos acompañaron y quizás impulsaron cambios importantes en las formas de identidad y el sentimiento religiosos. Cambios que han sido interpretados como parte de un proceso de secularización interna del mundo católico (Clark y Kaiser 2003; Dobbelaere 1994; McLeod 2000).

Los motivos del recorte espacial son tanto históricos como historiográficos. Tomo los casos de México y Argentina menos por sus similitudes (que son escasas), que por sus diferencias. La más evidente es la de las dimensiones de ambas Iglesias. En la actual Argentina, a comienzos de nuestro período, existían cuatro diócesis y hacia 1870 solo se sumó una, la del Litoral. Recién en 1865 existió una sede metropolitana en el territorio argentino; la de Buenos Aires. Hasta ese año, las diócesis rioplatenses eran sufragáneas de la de Charcas, ubicada en Bolivia. México, en cambio, contaba al iniciarse la década de 1840 con nueve obispados sufragáneos de la arquidiócesis de México. En nuestro período, la estructura diocesana creció considerablemente. Se desgajaron diez obispados de los anteriores, y las sedes de Guadalajara y Michoacán fueron elevadas a metropolitanas. Tenemos, entonces, al final del período diecinueve diócesis en México, reunidas en tres provincias eclesiásticas.

Las relaciones que entablaron las iglesias de estos dos espacios con los poderes políticos también son muy diferentes. Aunque en ambos casos hubo períodos de reforma (Ilamadas comúnmente liberales) que buscaron controlar mejor los mecanismos del gobierno eclesiástico y pasar a la administración estatal los bienes que estaban en manos de las instituciones religiosas, la enorme diferencia de escala entre los bienes eclesiásticos mexicanos y los rioplatenses definieron en gran medida el nivel del conflicto. ${ }^{2}$ En México, las autoridades eclesiásticas habían apoyado al poder civil desde la Independencia porque lo consideraban el mejor garante de la condición católica de la nación. Ese respaldo comenzó a flaquear a medida que fueron incrementándose de manera sostenida las demandas de auxilio económico que el Estado hacía en términos cada vez más perentorios a las arcas de la Iglesia. Las posiciones se fueron endureciendo hacia mediados de siglo. En la coyuntura de la guerra con Estados Unidos, afirma Connaughton (2010: 171-202), la alianza que habían fundado poder eclesiástico y civil sobre el proyecto de una nación católica se quebró, al menos a nivel nacional. El desenlace es de sobra conocido: entre 1859 y 1860 las llamadas "Leyes de Reforma» disolvieron los vínculos entre Estado e Iglesia en medio de una guerra que sacudió al país durante tres años. En comparación, el caso argentino no mostró grandes conflictos, a excepción de las escaramuzas de los años 1880 que tuvieron como punto más álgido la expulsión del Delegado Apostólico de la Argentina, pero que no llegó a provocar la ruptura del vínculo constitucional entre ambos poderes.

2 Para el caso argentino, Roberto Di Stefano (2004) señala, con buen criterio, que calificar como «liberales» estas políticas puede llevar a confusión porque, aunque en su política desamortizadora compartían los objetivos liberales, su rechazo a abandonar los mecanismos patronales que le daban participación en el gobierno eclesiástico los acercaba más a posturas galicanas que liberales.
En el plano historiográfico también existen diferencias para los dos casos. ${ }^{3}$ En México la historiografía eclesiástica tiene un gran desarrollo. El tema del conflicto entre liberalismo y catolicismo, y el de las relaciones entre Estado e Iglesia han sido objeto de numerosísimos estudios. ${ }^{4}$ No son tantos, sin embargo, los que se preocupan por los cambios que se vivieron en la manera de concebir y ejercer la autoridad dentro de la Iglesia durante el siglo XIX. ${ }^{5}$ Brian Connaughton $(2010,2015)$ ha destacado el carácter ambiguo del proceso que erosionó el esquema regalista colonial. Para el autor, las autoridades eclesiásticas en México no tenían al liberalismo como blanco fundamental de sus críticas antes de la crisis de mediados de la década de 1850, e incluso en esa crítica tardía el camino ultramontano de adhesión a la Santa Sede no fue el único que se abrió para la jerarquía diocesana de cara al rumbo liberal que fue adoptando la dirigencia política en ese período. Para Argentina, también existen trabajos que tratan el conflicto entre catolicismo y liberalismo en términos clásicos, identificando además esas fuerzas con las de la Iglesia y el Estado respectivamente hacia el último tercio del siglo XIX (Auza 1981; Bruno 1974). En los últimos años se ha renovado esa perspectiva y el interés se orientó hacia el rol que tuvieron el Estado, la Santa Sede y la naciente sociedad civil en la construcción institucional de la Iglesia moderna. En esta veta, se han planteado discusiones sobre las características del liberalismo argentino - que justificó frecuentemente la intervención del Estado para promover la expansión eclesiástica como un aspecto más del crecimiento institucional del país-, y el peso de Roma en la deriva de la Iglesia argentina, que fue adquiriendo gradualmente un perfil más congruente con el ideal ultramontano (Di Stefano 2011, 2013; Lida 2006b, 2007b; Martínez 2014a, 2014b, 2015, 2016).

La prensa religiosa ha sido estudiada también desde diferentes ángulos. Uno, clásico, la entendió como un arma blandida en el espacio público por autoridades eclesiásticas y laicos católicos en su lucha por frenar o reducir el impacto de políticas liberales y laicistas (Auza 1981; HibbsLissorgues 1995; Pani 1996; Ruiz Sánchez 2002). Dentro de esa línea, los estudios para México ofrecen diferentes interpretaciones. Algunos conservan la imagen tradicional de un catolicismo refractario a los rasgos de la modernidad y encuentran en las páginas de los periódicos que analizan una cabal expresión de esa intransigencia (Villaneda 1995; Fernández Fernández 2011, 2012) En cambio, Erika Pani (1996) y Brian Connaughton (2010) discuten la visión clásica según la cual los periódicos católicos solo representaban un agente retardatorio y retardado en el espacio político. Ambos demuestran que las posiciones del periodismo religioso y del clero planteaban alternativas políticas válidas al agitado siglo XIX mexicano.

Para ampliar en este punto, puede consultarse el estudio comparativo de Miranda Lida (2007a) sobre los desarrollos historiográficos en México y Argentina.

4 Entre los panoramas generales más recientes, pueden consultarse Connaughton 2010, Suárez Cortina et al. 2013; Suárez Cortina 2017. También es de suma utilidad la obra colectiva, coordinada por Álvaro Matute, Evelia Trejo y Brian Connaughton (1995)

5 Los trabajos dedicados a este problema suelen concentrarse en la labor reformadora de algunos obispos célebres por su postura ultramontana, como Pelagio Antonio de Labastida o Clemente de Jesús Munguía (García Ugarte y Rosas Salas 2016: 116-130). 
Por otro lado, un enfoque renovador analiza las condiciones socioculturales que hicieron posible la prensa religiosa. En palabras de Miranda Lida (2005: 117), se trata de determinar «... cómo se hacía un periódico católico, dónde y cómo se distribuía, quiénes eran sus lectores, por qué lo compraban y qué usos le daban». Es valiosa esta perspectiva porque entiende la prensa religiosa como algo más que un mero instrumento político o doctrinal de la jerarquía eclesiástica. Estos trabajos (Miranda Lida 2005, 2006a, 2012) muestran los usos que le daba la feligresía o el clero parroquial a estos periódicos como medio de expresión de sus intereses o como forma de comunicar necesidades y reclamos. Así, Lida vincula las novedades que se advierten en la prensa religiosa con los nuevos actores y prácticas asociativas de un mundo católico transformado por el proceso de modernización, que en las páginas de esos periódicos se rechazaba. ${ }^{6}$ Por último, en un trabajo reciente Roberto Di Stefano (2015) analiza la revista La Relijión (Buenos Aires, 1853-1862) como producto (pero también catalizador) del avance de las ideas ultramontanas en el mundo católico argentino y expresión de un nuevo actor, el laicado, surgido de prácticas y espacios asociativos también recientes en el espacio público porteño. Ambas novedades, ultramontanismo y laicado, son entendidas por Di Stefano como producto de la secularización, en la medida en que fueron posibles tras el abandono del régimen de cristiandad colonial. El ultramontanismo, al reconocer solo en la jerarquía eclesiástica, y fundamentalmente en el Papa, la capacidad de gobernar la Iglesia, suponía la separación entre esta y el cuerpo político (aunque la lamentara o intentara revertirla); y el laicado, al concebirse como un grupo dentro del conjunto social cuyo rasgo distintivo era la defensa de la religión, daba por sentado que ya no toda la sociedad estaba involucrada en esa defensa.

En este artículo, al igual que Lida y Di Stefano, considero la prensa religiosa de la segunda mitad del siglo XIX como parte del proceso de recomposición (y no retracción) religiosa en la modernidad (Hervieu-Leger 2008). Específicamente, me interesa tratar dos dimensiones de ese cambio. En un primer apartado, estudio la aparición (gradual y parcial) de formas y contenidos novedosos en la prensa religiosa, que puede obedecer a la intención de adaptarse a un nuevo perfil de lector, no solo, como ha señalado Lida (2006a), incorporando temas no estrictamente espirituales o de combate ideológico, sino también ajustando el discurso religioso a formas de sensibilidad más atractivas para un público más amplio. En la segunda sección de este artículo analizo las notas de contenido eclesiológico, que me permiten pensar estas revistas como instrumentos de una reforma del clero en clave ultramontana, lo que suponía un combate interno en la Iglesia contra las viejas doctrinas y hábitos galicanos heredados del período colonial. Al identificar similitudes en la prensa proveniente de dos situaciones tan distintas, la de México y la de la Argentina, es posible restaurar algunos rasgos de la transformación a escala global que experimentó el catolicismo en el largo siglo XIX.

La selección de los periódicos analizados obedece a diferentes criterios. Ante todo, el del recorte temporal del

\footnotetext{
6 Para un período más tardío en España ha trabajado este tema Lorena Romero Domínguez (2009)
}

trabajo, que toma un período temprano -incipiente más bien - de la prensa religiosa, entre fines de la década de 1840 y comienzos de la de 1870 . En segundo término, como el objetivo es complementar las investigaciones comentadas más arriba, se vuelve sobre las publicaciones que esos estudios abordaron.

Para el caso de Argentina, se toma La Relijión, publicada semanalmente en Buenos Aires entre 1853 y 1862. Se trató de una empresa colectiva que reflejaba, en palabras de Di Stefano (2015: 17) «... la emergencia de nuevas formas de sociabilidad católicas» en Buenos Aires. Según este autor, sus responsables obedecían a tres perfiles diferentes. En primer lugar, los eclesiásticos. Entre ellos, el clérigo Federico Aneiros (que sería arzobispo de Buenos Aires entre 1873 y 1894) y el dominico fray Olegario Correa fueron los impulsores de la iniciativa. El segundo grupo está conformado por letrados seglares, veteranos de las contiendas políticas de la época rosista. El más comprometido con la revista, y también el más relevante de los colaboradores pertenecientes a este grupo, fue Félix Frías. Por último, colaboró con la revista un conjunto de laicos pertenecientes a una generación más joven que la de Frías, que estarían en el centro de las discusiones de las décadas de 1870 y 1880, desatadas por iniciativas legislativas que buscaban incrementar la diferenciación entre Estado e Iglesia. Sus miembros más relevantes serían Miguel Navarro Viola y, particularmente, José Manuel Estrada (Di Stefano 2015: 28-32). A diferencia de lo que ocurrió con las revistas católicas mexicanas que aquí estudiamos, La Relijión nunca alcanzó el número de suscripciones necesario para autosustentarse. Los problemas que tuvo para afianzar una distribución nacional pueden explicar parte de ese fracaso. Al parecer, hubo escasos interesados en La Relijión fuera de Buenos Aires (adentro también) y aquellos pocos que se suscribían en las provincias, recibían los números de manera irregular y con demoras (Di Stefano 2015: 34-35).

En México el universo editorial era mucho más amplio. Se consideran aquí las siguientes revistas: El Católico, editado en la ciudad de México entre 1845-1847; El Espectador de México (México, 1851-1852) y La Cruz (México, 1855-1858), analizados ya por Erika Pani (1996) a los que se agregan EI Observador Católico, antecedente del Espectador, editado en México, entre 1848 y 1850 y La voz de México (publicado en México entre 1870 y 1875). Para estas publicaciones contamos con estudios que nos permiten conocer un poco mejor las condiciones y los responsables de su edición. El Católico, El Observador Católico y El Espectador de México fueron iniciativas sucesivas de un mismo grupo en el que destacaron las figuras de los sacerdotes Basilio José Arrillaga y su sobrino José Mariano Dávila y Arrillaga, de decidida intransigencia frente a las novedades en política. El principal impresor de las tres fue Rafael de Rafael y Vilá. Colaboraron en estas iniciativas otros personajes notables del mundo de las letras mexicano, como José Joaquín Pesado, Anselmo de la Portilla, José María Roa Bárcena, entre otros (Curiel et al. 2000, 2003). La Cruz estuvo vinculada al célebre obispo ultramontano Clemente de Jesús Munguía, que la dirigió en los primeros ocho o diez números. Luego la dirección pasó a manos de José Joaquín Pesado. El principal redactor fue José María Bárcena (Curiel et al. 2003; Gómez-Aguado de Alba 2002). Como se ve, los nombres se repiten y forman 
parte del grupo de dirigentes y publicistas conservadores de esos años. La Voz de México se publicó en un período posterior. Salía diariamente, a diferencia de los anteriores, que eran semanales. Hasta 1875 este periódico fue editado por la Sociedad Católica de México. En su último año los redactores decidieron desvincular La Voz de la Sociedad Católica para emprender una oposición más abierta y frontal con el gobierno (Curiel et al. 2003).

Las revistas mexicanas parecen haber tenido difusión en gran parte del país. Esa conclusión surge de la lista de puntos de distribución que publicaron oportunamente. La tríada de El Católico, El Observador y El Espectador fueron mejorando su red de corresponsales y puntos de distribución. Para comienzos de 1850 El Espectador se distribuía en dieciocho departamentos. También la calidad de la edición fue mejorando de número a número (Nava Martínez 2004: 57-58, 152-153). La Cruz contaba con una distribución lo suficientemente amplia para que las suscripciones solventaran el costo de las tiradas. La prensa liberal denunciaba que ese éxito se debía a que el clero funcionaba como agente de difusión (Gómez-Aguado 2002: 34). Eran sospechas que se alimentaban por la participación del obispo Munguía en la revista. A la par de su buena distribución, se adjudica a $L a$ Cruz un peso considerable en la opinión pública en discusiones tan importantes como las de la Constitución de 1857 (Curiel et al. 2003). La Voz, por su parte, contó con una muy extensa red de corresponsales y puntos de distribución, que coincidía con la estructura territorial de la Sociedad Católica. Entre 1870 y 1871 los corresponsales en todo el país pasaron de 75 a 86 . Las ventas parecen haber sido suficientemente altas para fundamentar el ataque del periódico liberal EI Siglo XIX hacia los responsables de La Voz, a quienes acusaba de procurarse «... a costa de los fanáticos una renta, y finca[r] una capellanía en la redacción, pagada por las viejas y los soñadores religiosos». ${ }^{7}$ Podemos afirmar entonces que las revistas mexicanas tenían una distribución territorial considerable y que, hacia el final de nuestro período, también el número de sus ventas era aceptable. Poco sabemos sin embargo del grupo social al que pertenecían esos lectores. Pero no es ese el propósito de este artículo, sino identificar las novedades señaladas arriba y asociarlas a los cambios que estaba viviendo el mundo católico a escala global. De todos modos, el lector puede ampliar parcialmente la información sobre estas revistas consultando la bibliografía citada.

\section{ARTEFACTOS MODERNOS}

De las varias novedades que introduce la prensa religiosa desde mediados del siglo XIX, me interesa aquí considerar dos. La frecuencia que adquieren las noticias de los avances del catolicismo en todo el mundo y sus victorias frente a la impiedad del siglo o a los abusos de los gobiernos, y el giro estético y temático que supuso una búsqueda de un público lector más amplio, menos dispuesto a seguir entrega tras entrega farragosos tratados jurídicos o teológicos y más propenso a entender la religión como una vivencia íntima, una devoción que funcionara asimismo como un reservorio de tradiciones edificantes y guía moral para el individuo.

\footnotetext{
«Un bofetón en el rostro». El Siglo XIX, 27/2/75, p. 2.
}

\section{El catolicismo a la conquista del mundo}

Por todas partes triunfa el catolicismo, y mil coronas ciñen sus sienes cada dia. El protestantismo que le declarara la guerra en el siglo XVI, y que hasta el presente aun domina en algunas naciones, manifiesta ya tal debilidad, que puede augurarse próximo su fin, así como el de la filosofía incrédula y sensual del siglo XVIII, que ha sumido á las naciones en un abismo sin fondo de males y desgracias

(El espectador de México, "Prospecto a La revista católica», 26/7/51).

En 1845, al presentarse al público en su primer número, El Católico se parangonaba con sus colegas:

... observamos que hay una multitud de periódicos dedicados esclusivamente á comunicarnos los sucesos mas notables que pasan en el mundo político, ¿̇no ha de haber uno consagrado á darnos noticia de cuanto suceda en el mundo religioso, de los combates y triunfos de sus ministros, de las conversiones de los protestantes, de los martirios y glorias de los héroes de la religion en diversas partes de la tierra, de todos los acontecimientos mas notables que sucedan en la iglesia católica? ${ }^{8}$

Sus redactores anunciaban que se habían suscripto a periódicos religiosos de Francia, Madrid, Roma, Inglaterra y Estados Unidos. Por eso estaban en condiciones de prometer «... que nada notable sucederá en el mundo religioso, que no publiquemos [...] Los católicos de toda la tierra son nuestros hermanos, y asi muy acreedores á que tomemos interés en tener noticia de sus trabajos ó satisfacciones». ${ }^{9}$

En considerable sintonía, La Relijión, de Buenos Aires, anunciaba en el número de su relanzamiento, en 1857:

[c]omo el catolicismo forma una sola familia de la gran familia humana, el periódico religioso debe ponernos en relacion con todo (sic) los miembros que estamos unidos por la fé, y por la caridad, bajo la cabeza visible de la Iglesia y vicario de Jesu-Cristo.

Por eso,

[I]os ejemplos sublimes que diariamente nos presenta la práctica de las virtudes cristianas en todo el mundo, comunicados, y transmitidos por la prensa diaria, que recorre toda la tierra, deben estimularnos á su imitacion; confirmando á la vez nuestra fé, por el conocimiento de que los siglos no la envejecen. ${ }^{10}$

En definitiva, los periódicos religiosos hispanoamericanos se insertaron bastante pronto en lo que Solange HibbsLissorgues (1995) llamó «internacional de la buena prensa», compuesta por un conjunto de revistas y periódicos católicos de Europa y Norteamérica que compartían opiniones, conductas y estrategias comunes.

¿Cuáles eran estas noticias? El Observador Católico publicaba, por ejemplo, que el rey de Prusia reconocía la obra de las Hermanas de la Caridad, que el rey de Java se había convertido al catolicismo y que, aunque expulsados de Buenos Aires, los jesuitas prosperaban en las provincias argentinas de Córdoba, San Juan de Cuyo y «Catamasco». ${ }^{11}$

\footnotetext{
El Católico, Ciudad de México, 30/8/1845, pp. 1 y 2.

Ibídem, p. 5.

10 La Relijión, Buenos Aires, 24/1/1857, p. 781

11 El Observador Católico, Ciudad de México, 15/4/48 y 20/5/48.
} 
La Relijión ofrecía en 1857 noticias internacionales, tomadas del periódico español Eco del mundo católico, donde se anunciaba la posibilidad de que algunos obispos de la iglesia anglicana volvieran al catolicismo en Inglaterra. Otra noticia provenía de Alemania donde los luteranos, se afirmaba, habían restituido la confesión auricular..$^{12}$ Los ejemplos son muchos: poblaciones italianas que resistían la desamortización de bienes de regulares, la expansión de las sociedades vicentinas por todo el mundo, el éxito de los jesuitas en oriente, etc.

En un libro muy sugerente Víctor Goldgel (2013) trabaja sobre el impacto que tuvo en la prensa periódica hispanoamericana del siglo XIX la irrupción de "la novedad», de "lo nuevo» como valor en sí mismo. Lo novedoso expresaba el ansia y la convicción compartidas de que la humanidad estaba entrando en un tiempo mejor. En el discurso de la prensa, sostiene Goldgel, ese valor intrínseco de la novedad se expresaba en una "retórica del entusiasmo». Como lo refleja tan claramente el epígrafe de esta sección, se puede pensar lo mismo para la prensa religiosa: la idea de que el siglo XIX es un siglo católico frente al XVIII, siglo impío de los filósofos y la revolución. También se entiende, en este contexto, el interés por entusiasmar a los lectores con los avances de la religión, con el éxito de las misiones y la conversión de protestantes.

La comunicación fluida con otros periódicos del mundo, la complicidad con los lectores en su avidez de noticias y novedades, la retórica del entusiasmo, eran todos rasgos propios de la sensibilidad pública moderna que los periódicos religiosos supieron combinar con un catolicismo que se estaba volviendo trasnacional en un sentido más amplio y profundo que el de la Iglesia universal: frente al avance de identidades territoriales de inédita intensidad, como las nacionalidades, o globales de fuerte carga revulsiva, como el socialismo, el catolicismo ultramontano buscó homogeneizar, en sus autoridades, principios y devociones, una identidad que trascendiera los nacionalismos y se enfrentara de igual a igual con las revolucionarias.

\section{Lecturas para gente moderna}

En un estudio muy interesante sobre la editorial fundada por don Bosco, Isotta Piazza (2009) da cuenta de los cambios de la prensa católica frente a la expansión del mundo lector en Italia, ocurridos a mediados del siglo XIX. Señala la autora que las autoridades eclesiásticas, al menos las italianas, ensayaron diferentes soluciones para captar al público menos instruido: debían evitar los tratados cerrados, largos y complejos que generaban aburrimiento o rechazo. En cambio, reflexionaban los publicistas católicos, «[p]ara esta generación de personas, que englobamos bajo el término vulgo, se requiere algo sensible, recreativo, conmovedor que entre por los sentidos y por la fantasía y así alcance el intelecto de la mejor manera posible $» .{ }^{13}$ En esa búsqueda, comenzaron a ganar espacio en las grandes editoriales (antes dedicadas a la publicación de densos tratados teológicos o filosóficos) obritas devocionales, como colecciones de preces, hagiografías, textos de catecismo, entre otros.

\footnotetext{
12 La Relijión, 14/3/57

${ }_{13}$ La Civiltà Cattolica, I (1850) 1, 99. Citado en Piazza (2009: 44) (traducción propia).
}

En las revistas que he consultado puede observarse una inercia que las lleva a continuar con la publicación de largos tratados que se prolongaban por semanas, incluso meses. No obstante, es clara también la intención de ampliar el espectro de lectores incorporando temas y textos más livianos y atrayentes. Ese propósito era expresado con frecuencia en los programas que solían publicar, como presentación, las revistas en sus primeros números.

El Católico manifestaba la preocupación de llegar a los inquietos lectores del siglo XIX. En su prospecto, decía su editor que era consciente de que las personas ocupadas huyen de los periódicos:

... porque para hallar en ellos alguna noticia importante, es preciso recorrer largas columnas de comunicados, historias y folletines, que si bien sean de mérito literario, pero importan muy poco á los que tienen atenciones graves y perentorias. El CATÓLICO hará, pues, una breve reseña de las noticias politicas mas importantes; y cuando el interes público lo exija, remitirá los lectores á los periódicos que traten la materia con mayor claridad. ${ }^{14}$

\section{El Observador Católico anunciaba en su presentación:}

[p]rocuraremos que El Observador Católico sea no solo útil, sino tambien agradable. Para lograr este fin, llamaremos á nuestro auxilio las flores de la poesía, y adornaremos sus páginas con los encantos de la bella literatura. Pero una literatura cristiana [...] En suma, haremos que El Observador Católico á la vez que no se desvíe ni un ápice de su importantísimo objeto, sea tambien un agradable instructor para el círculo doméstico, y un ameno compañero para las horas de descanso. ${ }^{15}$

Incluso La Relijión, que se mostró mucho más impermeable a las novedades formales que sus congéneres mexicanas, expresaba en el primer número de su segunda época, en el año 1857, que «[I]a instrucción difundida por un periódico religioso, debe acomodarse á toda clase de personas; y á todos los estados, y condiciones sociales». ${ }^{16}$ Pero sobre todo, debía acomodarse a los tiempos que corrían a una velocidad pasmosa. En efecto, La Relijión comparte un estupor ambiguo ante el imperio de lo nuevo con otros periódicos de la época. La ambigüedad radicaba en que, si bien los redactores no dejaban de advertir a sus lectores sobre los riesgos de otorgar valor a lo nuevo por el solo hecho de serlo, transmitían cada vez con más frecuencia todo aquello que pasaba en el mundo en píldoras de no más de ocho o diez líneas, y necesitaban de la novedad para mantenerse en marcha (Goldgel 2013). La presentación de La Relijión lo expresa muy claramente: en el periódico, «[e]l hombre de ciencia debe encontrar [...] el resumen, y el prontuario de cuanto hay esparcido en las voluminosas obras que forman su biblioteca». Pero a diferencia del placer que encuentra en comprobar el constante cambio que vive la ciencia, en las páginas del periódico podrá hallar

\footnotetext{
14 El Católico, 30/8/1845, p. 5
}

15 El Observador Católico, Ciudad de México, 25/3/1848, pp. 1 y 2. La cada vez más definida orientación de la prensa religiosa hacia el público femenino en un proceso de feminización de la religión ha sido ya estudiado (Crespo Sánchez 2015; Pacheco 2014; Stuven 2004)

16 La Relijión, 24/1/57, p. 780-782 
... diariamente nuevos ejemplos de acciones sublimes, producidas hoy por la doctrina católica, como lo han sido en el espacio de mil ochocientos años, y la satisfacion de que los héroes cristianos son de todos los lugares, y de todo los tiempos.

Trascartón, sigue el periódico interpelando a sus lectores:

El hombre de negocios debe tambien hallar en la lectura fugaz de un periódico religioso, el pensamiento y las máximas santas, que deben presidir a todas sus empresas, robustecidas por ejemplos [...] Hasta la imaginacion [de los artistas] debe encontrar en las bellezas del cristianismo, el placer que busca con avidez, y tras él cual corre sin cesar [...] Pero sobre todo el pueblo, que es el que mas necesita de instrucción, debe hallarla en una lectura amena, pues que no le es dado consagrarse a estudios profundos. ${ }^{17}$

La estrategia para llegar a un público más amplio, moldeado por los tiempos nuevos, no podía reducirse a satisfacer sus nuevos intereses, que los redactores del periódico reconocían - ¿ipara qué negarlo? - ajenos a la religión. El desafío era otorgar nuevas formas a las verdades que siempre había ofrecido la religión para que siguieran siendo útiles. Esas formas tenían que ver, como aparece constantemente en el texto citado, con lo fugaz, con la avidez, y con lo placentero.

A pesar de esta declaración de intenciones, muy poco se mueve La Relijión del esquema clásico de los periódicos de la primera mitad del siglo XIX: largos ensayos jurídicos, discusiones con otros periódicos que llevan semanas, transcripción de documentos oficiales y correspondencia de personas notables. ${ }^{18}$ Esporádicamente aparece la sección "Variedades» que, en ocasiones, contiene anécdotas moralizantes, donde el hombre moderno, entregado a los placeres más sensuales, termina reconociendo que nunca en su carrera mundana podrá escapar a la voluntad divina. ${ }^{19}$

Los periódicos de México parecen más proclives a la innovación. El Espectador de México, en un explícito esfuerzo por "complacer al público», matizaba las columnas escritas de sus páginas con litografías y grabados que hacían más llevadera la lectura. Además, sus redactores intentaban hacerse eco de la efervescencia cultural de esos años, por lo que publicaban a menudo críticas de obras teatrales y comentarios de libros. ${ }^{20}$ Si bien es cierto que solían hacerlo con el ya clásico espíritu de alarma y condena frente a la impiedad del tiempo, que caracterizaba el tono de la prensa católica desde fines del XVIII, el solo acto de reseñar estas obras y discutirlas, en vez de reclamar o publicar las censuras de la autoridad eclesiástica, habla de un cambio de actitud hacia el público lector.

La ciencia, como se anticipaba en los prospectos citados, también tuvo lugar en los periódicos, que discutieron sobre la frenología (El espectador de México), o el Mesmerismo, también conocido como magnetismo animal (La Relijión). Aquí, como en el caso de obras teatrales y literarias, los comentarios trataban de evitar la mera censura desde la autoridad del

\section{Ibídem, p. 781}

18 Roberto Di Stefano (2015) atribuye el fracaso comercial del periódico a su incapacidad para modernizar más profundamente sus formas y contenidos.

19 La Relijión, «Encuentro entre el arzobispo de Milán y un caballero muy poderoso", 31/1/57.

20 Este rasgo ya fue destacado por Nava Martínez (2004) dogma. Se las discutía con argumentos científicos o se las criticaba por sus efectos morales, muchas veces apelando a una moral difusa, cívica más que católica. En definitiva, se trataba de esfuerzos por colocar la mirada religiosa del mundo en un lugar diferente al de la autoridad y más cercano al de la utilidad, gran consigna de los prospectos relevados.

En la búsqueda de brindar al público esas breves píldoras edificantes recurrían los periódicos también a herramientas clásicas de la literatura religiosa, como los diálogos donde un incrédulo, un filósofo, un personaje soberbio, etc., recibían lecciones de humildad o piedad de simples devotos. Servían para crear una rápida imagen en el lector y una moraleja que pudiera ser fácilmente recordada y transmitida oralmente. En la misma línea, eran muy frecuentes las poesías breves, algunas con contenido religioso explícito, otras mucho menos evidente, pero todas de la más palmaria sencillez. Solo para graficar: El Espectador de México publicó este poemita firmado por J. J. Romea:

¿Qué hallé en la senda del vivir, Fortuna?

Sueños; iay! sueños, que veloz arruinas

Flores acaso; mas por cada rosa

¡Cuántas espinas! ${ }^{21}$

Señala Piazza (2009: 51) que Don Bosco trató de reproducir en sus ediciones el formato de la oralidad, consciente de que muchos textos llegaban al público analfabeto por medio de la lectura común en voz alta. En este sentido, el interés por publicar poesías y breves fábulas en los periódicos religiosos también puede estar dando cuenta de la intención de oralizar esos textos, no solo para su lectura en voz alta en medios analfabetos, sino para su fácil memorización y transmisión incluso en ausencia del periódico. ${ }^{22}$

En síntesis, las huellas de lo moderno en los periódicos estudiados no se manifiestan solamente en la incorporación de noticias no religiosas, que buscaban atraer la atención de un público que, al ritmo de la secularización, concebía al mundo separado en diferentes esferas. También fueron agentes del cambio religioso al difundir, de manera novedosa, formas nuevas de pensar el catolicismo.

\section{EL CATOLICISMO COMO ARENA DE BATALLA}

Así como la prensa religiosa intentó acceder a un público más amplio y al mismo tiempo representar y transmitir un catolicismo a la altura del siglo, también se ocupó de separar la paja del trigo. Por un lado, claro está, se dedicaba a condenar el mundo extramuros: los protestantes, los liberales, los masones, los apóstatas... Pero hacia adentro buscaba identificar quiénes eran los buenos miembros de la Civiltá Cattolica (tal fue el nombre de una de las publicaciones más influyentes del catolicismo ultramontano de esos años, publicada por los jesuitas en Roma) o cómo deberían pensar y actuar aquellos que se consideraban buenos católicos. ${ }^{23}$

21 El Espectador de México, 26/4/1851

22 La utilización de la poesía como herramienta moralizante y los intentos de modernizar las formas de transmisión de valores han sido señalados por Adriana Pacheco (2014) como parte de la política de la prensa religiosa mexicana orientada a «maternizar» la imagen femenina.

23 En este punto difiero de la interpretación de Nava Martínez (2004: 59), quien afirma que «... los redactores de las revistas [EI Católico, El Observador Católico, el Espectador de México] pensaron 
El sacerdote debía cumplir un rol clave en esas tareas de guía e instrucción. Sin embargo, en el espacio hispanoamericano, los eclesiásticos estaban lejos de presentar las condiciones adecuadas para convertirse en difusores y gendarmes del nuevo catolicismo. En el Río de la Plata, la vigencia del patronato y la inestabilidad institucional y política provocada por las crisis de independencia no habían hecho más que reforzar en los párrocos su afición hacia la agitada vida política local, de la que, en última instancia, dependía su futuro (Barral 2008). Con elocuencia lo señalaba Ildefonso García en una carta dirigida a Bartolomé Mitre y publicada en La Relijión el 14 de enero de 1854:

... desde que los curas han conocido que un prelado no significa nada y que su permanencia es precaria, se han hecho compadres del tintero mayor del pueblo ó cómplices del comandante y han confundido lo de patriota con lo de partidario, so pena de no durar cuatro días. ${ }^{24}$

En México, por su parte, las jerarquías eclesiásticas entraron no pocas veces en conflicto con sacerdotes que adherían, sea a principios galicanos, liberales, o una combinación de ambos, tan caros a gobiernos que los obispos consideraban hostiles a la Iglesia, como el de Valentín Gómez Farías o los que impulsaron las reformas de fines de la década de 1850 y principios de la de 1860 (Connaughton 2010).

Pero no era solo ese el problema: aunque los clérigos argentinos se propusieran abandonar los viejos «vicios» de connivencia con el poder local, o los mexicanos arriaran las banderas liberales, muy pocos sabrían cómo ejercer correctamente su ministerio. Las funciones básicas del párroco, como la de administrar los sacramentos y registrar su cumplimiento, el predicar o confesar, eran observadas de manera muy deficiente por sacerdotes que, al menos en el Río de la Plata, se habían educado en conventos, en universidades o en los pocos seminarios existentes, que transmitían muy mal los preceptos del concilio de Trento. La solución de fondo era evidente a los reformadores de estas Iglesias: establecer seminarios donde la correcta doctrina no fuera solo transmitida por los libros, sino también inculcada mediante la experiencia de aislamiento y disciplina (García Ugarte 2012; Martínez 2017). Pero esa empresa demoraría en dar sus frutos. En lo inmediato era necesario proveer a los párrocos de algunas coordenadas para orientarse en el camino. La prensa religiosa se pensó también con ese rol. Todavía en 1888 el entonces Vicario General, y luego arzobispo de Montevideo, Mariano Soler, reportaba a Roma con preocupación la supervivencia de estos vicios en el clero de todos los países hispanoamericanos. La prensa, junto a la enseñanza del catecismo y la organización del apostolado laico eran los medios que consideraba más adecuados para erradicarlos (Gaudiano Formento 1999).

He identificado dos clases de textos publicados en estos impresos que se orientan a ese fin. Una, más evidente, está integrada por artículos de contenido doctrinal y eclesiológico

que era más urgente defender a la iglesia y, por ende, a la religión, que catequizar, pues para eso ya existían otros instrumentos». Mi argumento aquí es que las revistas participaron de una disputa interna por el control de esos instrumentos.

24 p. 187. abiertamente destinados a discutir en todo o en parte los principios galicanos y regalistas. La otra, menos inclinada a la confrontación, está compuesta de sermones y otros textos de carácter pastoral o devocional que eran pensados como insumos para los párrocos que, al ser publicados con la venia episcopal, gozaban de una ortodoxia certificada. ${ }^{25}$

\section{Faros de la nueva ortodoxia}

Si pues hay una discrepancia completa, una verdadera lucha de doctrinas, y por otra parte una protesta igual en favor de la religion y del Evangelio, nada nos parece mas interesante hoy dia como disipar estas tinieblas, despejar esta incógnita, y ver, en fin, en cuál de las dos partes figura la religion y el Evangelio como una realidad, y en cuál como una ilusion... (La Cruz, 1/11/55, p. 4).

La primera de estas modalidades está muy presente en el periódico porteño La Relijión. Por ejemplo: durante cuatro entregas, entre el 26 de noviembre y el 17 de diciembre de 1853 , se publicó una larga reseña y condena realizada por el obispo de Cuenca a la obra de Francisco de Paula Vigil, portadora de un título más que sugerente: Defensa de la autoridad de los gobiernos y de los obispos contra las pretensiones de la Curia romana (Lima, 1849). Es interesante aquí identificar con qué argumentos se discutían las viejas posiciones galicanas. Uno particularmente importante es el que apunta al criterio de autoridad. Era usual en el discurso jansenista (cantera frecuente de las posturas galicanas) cuestionar las prerrogativas de la jerarquía eclesiástica recurriendo a las imágenes de una Iglesia primitiva que era a la vez más horizontal y más verdadera, por estar cercana a su fundador Jesucristo. A ese pasado ideal remitía Vigil para cuestionar la legitimidad de los diezmos y primicias, que no habrían existido en los comienzos cristianos. La respuesta publicada en La Relijión no se embarcaba en una discusión bizantina sobre las fuentes históricas del diezmo, siguiendo la lógica del autor galicano. Simplemente cambiaba el criterio de autoridad:

[c]omo nuestro ministerio pastoral se reduzca á enseñar la disciplina presente, decimos á nuestros diocesanos que poco ó nada nos importa la cuestion de derecho divino: la Iglesia ha mandado que se paguen diezmos y primicias en virtud de la potestad que ha recibido de Jesucristo; y querer derogar este precepto es una rebelion manifiesta, asi como ningun particular tiene derecho para quebrantar una ley civil so pretesto de que no es de derecho divino, ó que no es justa. ${ }^{26}$

Es claro aquí el peso que tiene el sentido moderno de ley como instrumento privilegiado de gobierno, en contraste con la lógica imperante en el Antiguo Régimen, donde el acto de gobernar era asociado a la administración de una justicia trascendente y equitativa, más que a la aplicación estricta de la norma (Cardim 2001; Garriga 2004). Ildefonso García, en la carta a Mitre citada más arriba, se coloca en

25 A diferencia de lo que afirma Pineda-Soto (2009) para los periódicos religiosos de Michoacán de las últimas décadas del siglo XIX, no encuentro una división clara entre las publicaciones destinadas a la devoción y las que tenían un propósito "político-religioso». Quizás esa separación corresponda a un nivel de complejidad mayor de la prensa de fines de siglo.

26 La Relijión, 10/12/1853, p. 121. 
el mismo plano. El mal de la sociedad es moral, sostenía, y «...el único remedio es la Religion y no cualquiera sino la verdadera. [L]os principales ministros de ella son el Romano Pontífice y sus coadjutores». ${ }^{27}$

La discusión entre quienes encontraban la verdad en la autoridad pontificia y aquellos que preferían buscarla en los origines asamblearios del cristianismo primitivo también tuvo eco en la prensa religiosa mexicana. La cita que abre este apartado pertenece a un artículo titulado «Autoridad docente de la Iglesia» que se publicó en el periódico La Cruz como parte de una serie de notas destinadas a fijar el rumbo de la sana doctrina, bajo el título "La cuestión Religiosa». Como se anticipa en el fragmento, el periódico identifica quiénes son portadores de la verdad religiosa y cuáles, por el contrario,

\begin{abstract}
... abrigando en su interior las mismas ideas y los mismos sentimientos [que los ateos], varían de estrategia, y se colocan bajo la bandera cristiana para destruir el reino mismo de Jesucristo. Esta clase de adversarios son mas difíciles de combatir, porque están dentro de casa, afectan profesar el catolicismo y se muestran ardientemente deseosos de ver aparecer de nuevo los tiempos primitivos. ${ }^{28}$
\end{abstract}

En esta puja, los periódicos podían recurrir a muy actuales autores ultramontanos. El Observador Católico, por ejemplo, publicó durante tres números un artículo de Donoso Cortés extraído del peninsular El Español, donde se explicaba el carácter de las reformas que Pio IX estaba aplicando en los Estados Pontificios. Su llegada a la cátedra de san Pedro, entendía el autor, marcaba el triunfo de una de las dos líneas que se habían enfrentado dentro de la Iglesia. Por un lado, estaban los que creían necesario conservar los fuertes vínculos que habían unido el poder eclesiástico al civil. Esa postura, sostenía, había provocado la caída de las Iglesias junto con las monarquías en la era de las revoluciones. Por el otro lado,

[v]arones eminentísimos comenzaron á sospechar que era una grave falta en la Iglesia, apoyarse, siendo eterna como lo es, en lo que es efímero y deleznable; es decir, en las potestades humanas [...]. Entonces nació y creció ese gran partido que está dispuesto á renunciar, en nombre de la Iglesia, á todas las alianzas y á todos los protectorados, por reconquistar la libertad primitiva: libertad augusta, libertad santa que ha de llevar la Iglesia del Señor á todos los confines del mundo, que la ha de entregar libremente rendidos á sus piés á todos los pueblos, que ha de poner la Cruz en mayores alturas para que la adoren las gentes. Esa opinion, por no decir esa partida, ha subido al pontificado con Pio IX, y al encarnarse en su santísima persona, se ha encarnado en el mas eminente de todos los príncipes y en el mas augusto de todos los hombres. ${ }^{29}$

La batalla, sin embargo, fue larga. La Voz de México publicaba todavía en 1870 una nota tomada del célebre periódico francés L'Univers donde se condenaban los textos del sacerdote Auguste Gratry en torno a la infalibilidad papal y aseguraba que las posturas galicanas, que encontraban en Gratry su abogado, estaban prontas a desaparecer. ${ }^{30}$

\section{Hojas de ruta}

El será tambien el auxiliar poderoso, é incesante del clero, en su ministerio de predicaciones; y suplirá en nuestros desiertos lo que no puede hacer el celo mas ferviente de los curas de nuestra campaña [...] Destinado á repetir, y á multiplicar la accion de los ministros del Evangelio, debe ser un eco, que resuene hasta en el mas lejano y escondido rincon (La Relijión, 24/1/1857, p. 781).

El epígrafe, extraído del programa de La Relijión en el número de su relanzamiento, habla del rol que se asigna al periódico. Una lectura suspicaz de este fragmento revela que, más que como auxiliar, los redactores piensan su revista como una guía para la labor del párroco. Porque ¿quién si no el sacerdote era ese lector destinado a recibirla «en el más lejano y escondido rincón» de "nuestros desiertos»? Este propósito está en consonancia con la evaluación que del clero hacían la jerarquía eclesiástica de Buenos Aires y la de las demás provincias argentinas (Martínez 2017). Frente a la convicción (justificada o no) de que los rústicos pastores rioplatenses, librados a su criterio, serían incapaces de guiar por el recto camino a sus ovejas, les ofrecían en las páginas de La Relijión todo un menú de recursos que contaban con la venia episcopal.

No eran solo los prelados rioplatenses quienes pensaban que era mejor ofrecer a sus párrocos homilías y ejemplos de piedad prefabricados, listos para usar. El periódico mexicano El Católico, en su prospecto de 1846, anuncia que todas las semanas publicará una homilía sobre la lectura del evangelio que se haría la semana siguiente a la aparición de cada número. Se aclara que está destinado a la feligresía, pero también a los sacerdotes, esperando que «tengan abundantes y escogidos materiales para llenar el pesado é indispensable deber de la predicacion semanal á sus feligreses». ${ }^{31}$ En definitiva, el interés por publicar notas de contenido piadoso y devocional en la prensa religiosa no es necesariamente "un testimonio de la tradición religiosas (sic) del siglo XIX» (Pineda-Soto 2009: 19). Por el contrario, puede ser una estrategia para modificar antiguas sensibilidades que contradecían el nuevo modelo de Iglesia y religiosidad que los editores de estos periódicos y las autoridades eclesiásticas estaban impulsando.

Orientar, cuando no disciplinar, a los sacerdotes era una tarea delicada para el periodismo religioso. Cualquier reconvención demasiado explícita podía dar pasto a los siempre alertas redactores anticlericales de los periódicos con los que discutían (que no eran pocos). Es más, están plagadas las páginas de esta prensa de elogios a la figura sacerdotal. De todas maneras, los redactores se las ingeniaban para señalar algunas faltas y marcar el camino deseado. La Relijión, por ejemplo, publicó un «Diálogo entre un Sacerdote joven y un anciano seglar» en el que el anciano criticaba a los periódicos que atacaban a los sacerdotes, pero también a los clérigos que no actualizaban sus sermones y hacían poco atractivo el discurso a la feligresía. ${ }^{32}$ El mismo semanario había anunciado el año anterior la reanudación de las conferencias morales del clero. En el próximo encuentro,

\footnotetext{
27 La Relijión, 14/1/1854, p. 188.

28 La Cruz, 1/11/55. p, 5.

29 El Observador Católico, 15/4/48, p. 80.

30 La Voz de México, 17 y 26/4/1870.
}

31 El Católico. México, «Prospecto» dentro de «Programa», 1846 $(\mathrm{s} / \mathrm{f})$

32 La Religión, 11/12/1858, pp. 618-620. 
comentaba, se trataría sobre el tiempo que debía durar la celebración del santo sacrificio de la misa. ${ }^{33}$

Incluso a través de la publicidad las páginas de estos periódicos señalaban a los curas cuáles eran sus deberes de pastor. La Voz de México publicó el siguiente aviso «A los párrocos»:

En los pueblos ha llegado á ser adagio decir que todo anda como el reloj de la parroquia, es decir, muy mal, pues los mas de estos, de tan viejos están chochando, indicando las 9 cuando son las 12 , ó al revés, y por lo mismo tocan la Alba á las 8, las oraciones á las 9 ó las 10, y la queda a media noche, y así de todo con gran perjuicio de los fieles, á quienes esos desarreglos para llamarles á misa y á los oficios divinos causan insensiblemente el relajamiento que se nota en sus deberes religiosos.

Para remediar este problema, anunciaba el periódico, Pablo Leautaud había pedido «de las mejores fábricas de Europa cierto número de relojes modernos con carátulas iluminables, maquinaria de toque, etc. ${ }^{34}$

\section{CONCLUSIÓN}

Está ya bastante consensuada entre los historiadores de la religión la idea de que, con el advenimiento de la sociedad moderna, el catolicismo no se encerró en sus antiguas formas para rechazar los cambios del entorno, sino que también él mutó. En este trabajo intenté dar un panorama general de algunos rasgos de la prensa religiosa del tercer cuarto del siglo XIX que nos permiten pensarla como un agente renovador dentro del catolicismo.

No obstante, el modo en que se transformó en este contexto fue, por cierto, particular. Joseph Komonchak (1997: 356) sostiene que en

\section{... los siglos XIX y XX la Iglesia Católica construyó para sí misma una nueva forma sociológica que difería en modo significativo del catolicismo previo. Este Catolicismo romano moderno tomó la forma de una contra sociedad, legitimada por una contracultura como una respuesta y en oposición a las emergentes cultura y sociedad liberales.}

En razón de las características «contraculturales» que menciona Komonchak, ese carácter renovador tendía a ser ocultado por los mismos redactores, que negaban a lo moderno todo valor. Pero ese no era, entiendo, el único motivo para disimular las novedades que transmitían los periódicos analizados. Embarcados en una pugna por la definición del catolicismo verdadero frente a otras formas posibles de adecuarlo a los tiempos, sus redactores negaban el carácter histórico y contingente de las ideas que intentaban imponer.

Esa imposición siguió un doble movimiento. Por un lado, se adaptó suficientemente en las formas y los contenidos al contexto político, cultural y social del siglo XIX. En gran medida la adaptación en las formas es entendida como centralización y universalización del catolicismo. En su contenido, el discurso ultramontano compartía también los rasgos de los lenguajes políticos con los que disputaba: hizo

\footnotetext{
33 La Religión, $18 / 4 / 1857$, p. 871

34 La Voz de México, 4/6/1870
}

del concepto de libertad, e incluso de libertad religiosa su caballo de batalla contra las pretensiones patronales de los poderes civiles, defendió la potestad de la norma frente a la costumbre en su intento de erradicar posturas galicanas dentro del clero, fortaleció una identidad católica supranacional con unidad de causas e intereses.

Doble movimiento, decía, porque además de acompañar a su modo el mundo en cambio, las formas y discursos ultramontanos debieron rivalizar con otras formas de organizar y entender la iglesia. Si bien en países como Francia (y quizás también en España) el conflicto más sonado fue con el catolicismo liberal, en Hispanoamérica el contrincante fue la ya mencionada tradición galicana, en las que se había formado el clero durante la época tardocolonial y las primeras décadas del período independiente.

\section{BiBLIOGRAFÍA}

Auza, Néstor Tomás. 1981. Católicos y liberales en la Generación del Ochenta. Buenos Aires: Ministerio de Cultura y Educación.

Barral, María Elena. 2008. «De mediadores componedores a intermediarios banderizos: el clero rural de Buenos Aires y la paz común en las primeras décadas del siglo XIX». Anuario IEHS 23: 151-174.

Bruno, Cayetano. 1974. Historia de la Iglesia en Argentina. Vol. X. Buenos Aires: Don Bosco.

Cardim, Pedro. 2001. «Religão e ordem social : Em torno dos fundamentos católicos do sistema político de Antigo Regime». Revista de História Das Ideias 22: 133-174. https://doi. org/10.14195/2183-8925_22_6

Clark, Christopher y Wolfram Kaiser. 2003. Culture Wars: SecularCatholic Conflict in Nineteenth-Century Europe. Cambridge, U.K.; New York: Cambridge University Press.

Connaughton, Brian Francis. 2010. Entre la voz de Dios y el llamado de la patria : religión, identidad y ciudadanía en México, siglo XIX. México, D.F: Universidad Autónoma Metropolitana - Fondo De Cultura Económica.

Connaughton, Brian Francis. 2015. "¿Reformar una "sociedad perfecta"? Objetivos disputados y actores encontrados. La Iglesia Mexicana en la secuela a la Independencia nacional». Itinerantes. Revista de Historia y Religión 5: 91-120.

Crespo Sánchez, Francisco Javier. 2015. «Un modelo de familia católica en la prensa mejicana del siglo XIX. Ejemplos a partir de del Seminario Católico». Naveg@mérica. Revista Electrónica editada por la Asociación Española de Americanistas 14 [En Línea] Disponible en: <https://revistas.um.es/navegamerica/article/ view/224581>

Curiel, Guadalupe, Miguel Ángel Castro y Martha Celis de la Cruz. 2000. Publicaciones periódicas mexicanas del siglo XIX, 1822-1855: Fondo Antiguo de la Hemeroteca Nacional de México. México: Universidad Nacional Autónoma de México. [En Línea] Disponible en: <http://www.elem.mx/obra/datos/93146>

Curiel, Guadalupe, Miguel Ángel Castro y Martha Celis de la Cruz. 2003. Publicaciones periódicas mexicanas del siglo XIX, 1856-1876: Fondo Antiguo de la Hemeroteca Nacional de México. México: Universidad Nacional Autónoma de México. México: Universidad Nacional Autónoma de México. [En Línea] Disponible en: <http:// www.elem.mx/obra/datos/93146>

Di Stefano, Roberto. 2004. El púlpito y la plaza. Clero, sociedad y política de la monarquía católica a la república rosista. Buenos Aires: Siglo XXI.

Di Stefano, Roberto. 2011. «Por una historia de la secularización y de la laicidad en la Argentina». Quinto Sol 15: 1-32.

Di Stefano, Roberto. 2013. "Sobre liberalismo y religión: Rentas eclesiásticas y presupuesto de culto en el Estado de Buenos Aires (1852-1862)». Almanack 5: 178-98. [En línea]. Disponible en: http://www.almanack.unifesp.br/index.php/almanack/article/ view/982. 
Di Stefano, Roberto. 2015. «La revista La Relijion (1853-1862) y la formación de un círculo intelectual ultramontano en Buenos Aires». En Manifestações do pensamento católico na América do Sul, editado por Cândido Moreira Rodrigues, Gizele Zanotto y Rodrigo Coppe Caldeira, 13-39. São Paulo: Fonte Editorial.

Dobbelaere, Karel. 1994. Secularización: un concepto multi-dimensional. México D.F.: Universidad Iberoamericana.

Fernández Fernández, Íñigo. 2011. «La prensa de la ciudad de México: un espacio de confrontación entre la Iglesia y el Estado. 18331857». En Fiscalidad, medio ambiente y cohesión social en el pensamiento liberal atlántico (siglo XIX). Análisis de casos, editado por María Eugenia Claps y Pedro Pérez, 31-55. Alcalá: Instituto de Estudios Latinoamericanos, Universidad de Alcalá.

Fernández Fernández, Íñigo. 2012. «¿Toda verdad, diga quien la diga, viene del Espíritu Santo? La defensa de los vínculos enrte la fe y la razón en la prensa católica de la capital mexicana (1833-1857)». Studuim. Revista de Humanidades 18: 99-124.

García Ugarte, Marta Eugenia. 2012. «Proyectos de formación eclesiástica en México (1833-1899)». Lusitania Sacra 26: 25-54.

García Ugarte, Marta Eugenia y Sergio Francisco Rosas Salas. 2016. «La Iglesia Católica en México desde sus historiadores (1960-2010)». Anuario de Historia de La Iglesia 25: 91-161.

Garriga, Carlos. 2004. «Orden jurídico y poder político en el Antiguo Régimen». Istor. Revista de Historia Internacional 16: 13-44.

Gaudiano Formento, Humberto Pedro. 1999. «Mons. Mariano Soler, primer arzobispo de Montevideo, y el Concilio plenario latino americano». Excerpta e Dissertationibus in Sacra Theologia XXXVII: 375-462. [En línea] Disponible en: <http://hdl.handle. net/10171/11610>

Goldgel, Víctor. 2013. Cuando lo nuevo conquistó América: Prensa, moda y literatura en el siglo XIX. Buenos Aires: Siglo Veintiuno Editores.

Gómez-Aguado de Alba, Guadalupe Cecilia. 2002. Un proyecto de nación clerical. Una lectura de La Cruz. Periódico exclusivamente religioso. Tesis de Maestría del Instituto de Investigaciones Dr. José María Luis Mora [En línea] Disponible en: https://biblioteca.mora.edu.mx/exlibris/aleph/u22_1//objects/mor01/ indice/2/000143062.pdf

Hervieu-Leger, Danièle. 2008. «Producciones religiosas de la modernidad». En Modernidad, religión y memoria, editado por Fortunato Mallimaci. Buenos Aires: Colihue.

Hibbs-Lissorgues, Solange. 1995. Iglesia, prensa y sociedad en España. Alicante: Instituto de Cultura Juan Gil Albert y Diputación de Alicante.

Komonchak, Joseph A. 1997. "Modernity and the Construction of Roman Catholicism». Christanesimo nella Storia 18: 536-585.

Lida, Miranda. 2005. "La prensa católica y sus lectores en Buenos Aires, 1880-1920». Prismas 9: 119-131.

Lida, Miranda. 2006a. «Prensa católica y sociedad en la construcción de la Iglesia argentina en la segunda mitad del siglo XIX». Anuario de Estudios Americanos 63 (1): 51-75. https://doi.org/10.3989/ aea.2006.v63.i1.3

Lida, Miranda. 2006b. «Una Iglesia a la medida del Estado: la formación de la Iglesia nacional en la Argentina, (1853-1865)». Prohistoria 10: 27-46.

Lida, Miranda. 2007a. «La Iglesia católica en las más recientes historiografías de México y Argentina. Religión, modernidad y secularización». Historia Mexicana 56 (4): 1393-1426.

Lida, Miranda. 2007b. «El presupuesto de culto en la Argentina y sus debates. Estado y sociedad ante el proceso de construcción de la Iglesia (1853-1880)». Andes 18: 49-75.

Lida, Miranda. 2012. La rotativa de Dios prensa católica y sociedad en Buenos Aires. El pueblo (1900-1960). La Argentina contemporánea. Buenos Aires: Editorial Biblos.
Martínez, Ignacio. 2014a. «Circulación de noticias e ideas ultramontanas en el Río de la Plata tras la instalación de la primera nunciatura en la América ibérica (1830-1842)». Historia Crítica 52: 73-97.

Martínez, Ignacio. 2014b. «Desarrollo de la intransigencia católica en Argentina durante la primera mitad del siglo XIX». En Representaciones sobre historia y religiosidad. Deshaciendo fronteras, editado por Ana Cecilia Aguirre y Esteban Abalo, 113-127. Rosario: Prohistoria.

Martínez, Ignacio. 2015. «Nuevos espacios para la construcción de la Iglesia: Estado nacional y sectores ultramontanos en la Confederación Argentina, 1853-1862». Quinto Sol 19 (3): 1-23.

Martínez, Ignacio. 2016. «Consolidación del discurso ultramontano y clero intransigente en el Río de la Plata: 1820-1865». En Historias de clérigos y religiosas en las Américas: conexiones entre Argentina y Brasil (siglos XVII -XIX), editado por Valentina Ayrolo y Anderson José Machado de Oliveira, 349-392. Buenos Aires: Teseo.

Martínez, Ignacio. 2017. «Reforma ultramontana y disciplinamiento del clero parroquial. Diócesis de salta 1860-1875». Andes 28 (2) [En línea] Disponible en: <http://www.redalyc.org/articulo. oa?id=12754970001>.

Matute, Alvaro, Evelia Trejo y Brian Francis Connaughton (eds.). 1995. Estado, Iglesia y sociedad en México, siglo XIX. México: Facultad de Filosofía y Letras UNAM Grupo Editorial M.A. Porrúa.

McLeod, Hugh. 2000. Secularisation in Western Europe, 1848-1914. New York: St. Martin's Press.

Nava Martínez, Othón. 2004. La propuesta cultural del grupo conservador vista a través de las revistas católicas mexicanas, 1845-1852. Tesis de Maestría del Instituto de Investigaciones Dr. José María Luis Mora [En línea] Disponible en: <https://biblioteca.mora.edu. mx/exlibris/aleph/u22_1//objects/mor01/vista/2/000143984.pdf>

Pacheco, Adriana. 2014. «Periódicos católicos mexicanos del siglo XIX. Conformación de la madre de familia durante la República Restaurada para trabajar por "el otro México"». Tinkuy. Boletín de Investigación y Debate 21: 75-90.

Pani, Erika. 1996. «Una ventana sobre la sociedad decimonónica: los periódicos católicos, 1845-1857». Secuencia 36: 67-88. https:// doi.org/10.18234/secuencia.v0i36.550

Piazza, Isotta. 2009. "Un'editora cattolica per il popolo». En Chiesa e cultura nell'Italia dell'Ottocento, editado por Edoardo Barbieri, 37-63. Brescia: Morchelliana.

Pineda-Soto, Adriana. 2009. La prensa religiosa y el estado liberal en el siglo XIX: La perspectiva michoacana. Red de Historiadores de la prensa y el Periodismo en Iberoamérica. [En línea] Disponible en: <redestudiosprensa.mx/hdp/files/116.doc>

Romero Domínguez, Lorena R. 2009. La buena prensa: prensa católica en Andalucía durante la Restauración. Sevilla: Centro de Estudios Andaluces.

Ruiz Sánchez, José-Leonardo. 2002. Prensa y propaganda católica: (1832-1965). Sevilla: Universidad de Sevilla.

Stuven, Ana María. 2004. "Ser y deber ser femenino: "La Revista Católica". 1843-1874». En Construcciones impresas. Panfletos, diarios y revistas en la formación de los estados nacionales en América Latina, 1820-1920, editado por Paula Alonso, 243-271. México: Fondo de Cultura Económica.

Suárez Cortina, Manuel. 2017. «Religión, Estado y Nación en España y México en el siglo XIX: una perspectiva comparada». Historia Mexicana 67 (1): 341-400. https://doi.org/10.24201/hm.v67i1.3446

Suárez Cortina, Manuel, Evelia Trejo y Aurora Cano Andaluz (eds.). 2013. Cuestión religiosa: España y México en la época liberal. Santander: Editorial de la Universidad de Cantabria.

Villaneda, Alicia. 1995. «Periodismo confesional: prensa católica y prensa protestante, 1870-1900». En Estado, Iglesia y sociedad en México, siglo XIX, editado por Alvaro Matute, Evelia Trejo y Brian Francis Connaughton, 325-366. México: Facultad de Filosofía y Letras UNAM Grupo Editorial M. A. Porrúa. 